\title{
Understanding Bereavement among College Students: Implications for Practice and Research
}

\author{
Cristina Bistricean $^{1}$ and Munyi Shea ${ }^{2}$ \\ ${ }^{1}$ Senior Lecturer, Central Washington University, USA \\ ${ }^{2}$ Professor of Counselor Education, School of Education, Seattle Pacific University,
} USA

\begin{abstract}
The experience of losing a first-degree family member, followed by a second-degree family, and a close friend is prevalent among college students. Bereavement affects student success as they must balance grief and academics. Culture also influences the expression and experience of grief, making it essential to understand grief and bereavement in context. The recent COVID-19 global pandemic has exacerbated the experience of loss and grief among college students, which warrants a better understanding and intervention for disenfranchised grief. Social and emotional support for disenfranchised grief is not always provided, as this type of grief is often socially unsanctioned. The lack of support and understanding could make it difficult for individuals with disenfranchised grief to cope with the demands of higher education and the bereavement process. Counseling implications for how universities and colleges could intervene on the bereaved student's behalf are discussed.
\end{abstract}

Keywords: bereavement, grief, disenfranchised grief, college student, higher education

\footnotetext{
Author Note

Cristina Bistricean (1) https://orcid.org/0000-0002-2832-0386

Munyi Shea (D) https://orcid.org/0000-0002-0273-4038

We have no known conflict of interest to disclose.

Correspondence concerning this article should be addressed to: Dr. Munyi Shea, 3307 3rd AVE

W, Seattle WA 98119. Email: mshea@spu.edu.
} 
Understanding Bereavement among College Students: Implications for Practice and Research

\section{Understanding Bereavement among College Students:}

\section{Implications for Practice and Research}

Bereavement in higher education remains prevalent and affects student success (Balk, 2008; Balk et al., 2010; Cox et al., 2015). Experiencing a loss can be debilitating and is considered a significant life event (Neimeyer et al., 2008). Balk (2011b) identified bereavement as "the normal human responses to a deep misfortune" (p. 7). Balk (2008) conducted a comprehensive analysis of studies related to bereaved college students and found that about onethird of college students are in bereavement at any given time. Specifically, research indicates that $30 \%$ to $36 \%$ of students report a loss within the first 12 months of their academic study (Balk et al., 2010; Cox et al., 2015), and 37\% to 44\% experience a loss within 24 months (Cousins et al., 2017; Cox et al., 2015). Overall, 60\% of college students report having lost at least one person close to them by the end of their academic career (Cox et al., 2015). Current studies are needed to adequately capture the bereavement rates for college students.

The complications experienced by bereaved individuals are broad and multidimensional. For instance, they may suffer from impaired cognitive functioning - including memory loss, inability to focus, losing one's identity and trying to search for the meaning of the loss. They may also experience emotional difficulties - including dysphoria with anger, yearning, and loneliness (Balk, 1997; Bonanno \& Kaltmann, 2001; Maciejweski et al., 2007). Grieving could also impact bereaved individuals' social spheres and contribute to their physical and psychological pain (Cox et al., 2015: Neimeyer et al., 2008). Research has documented the negative impact of bereavement on college students' academic development, such as lower GPAs, fewer completed credits, higher likelihood of being placed on academic probation, and increased risk of dropping out (Servaty-Seib \& Hamilton, 2006). Approximately 30\% of bereaved college students drop out 
Understanding Bereavement among College Students: Implications for Practice and Research

before their sophomore year, which could reduce their earning potential by $\$ 21,000$ per year and on average, acquire a student loan debt of $\$ 37,000$ (Bustamante, 2019).

Not only are individuals who identify as BIPOC (Black, Indigenous, Person of Color) disproportionally impacted by the COVID-19 pandemic (West, 2020), they may also grieve differently than Whites because of their cultural context (Boulware \& Bui, 2016; Inman et al., 2007; Laurie \& Neimeyer et al., 2008; McDevitt-Murphy et al., 2012; Oltjenbruns, 1998;

Schoulte, 2011). The approach to support bereaved students of color has been primarily Eurocentric. For example, the Eurocentric view of bereavement support requires working through grief with structured intervention, requiring counseling and possibly medication. It rarely considers traditions, rituals, values, and cultural beliefs (Moore et al., 2020).

Altogether, the prevalence of bereavement among college students and the negative impact on their physical and mental health warrants a better understanding and development of a culturally responsive intervention. This paper attempts to highlight the different types of grief and bereavement experienced by students in higher education, the impact of bereavement on the college population, especially along the lines of cultural diversity, and understand the effects of disenfranchised grief on students.

\section{Overview of Bereavement, Mourning, Grief, Complicated Grief, Disenfranchised Grief}

Bereavement, mourning, grief, and complicated grief are often used interchangeably (Shear, 2012). Balk (2011b) wrote, "Bereavement refers to being in a state of loss, grief to the reactions in being bereaved, and mourning to expressions of one's grief" (p. 3). There are distinct differences between the definitions (Stroebe et al., 2008), and knowing the difference makes it easier to ascertain experiential and emotional contrasts (Stroebe et al., 2001). Stroebe et al. (2008) define bereavement as an objective experience of loss when a bereaved individual has lost 
Understanding Bereavement among College Students: Implications for Practice and Research

a loved one or someone of significance (i.e., first-degree family members or close friends) through death.

Grief is a common emotional response during bereavement (Shear, 2012; Stroebe et al., 2001) and can manifest in various ways. Bonanno and Kaltman (2001) stated, "Grief is a painful, but unfortunate common experience" (p. 705). The grief reactions are usually prevalent anywhere from six months to one year after a loved one's death and eventually lessen in intensity as time goes by (Bonanno et al., 2002; Schnider et al., 2007; Shear \& Mulhare, 2008). Grief often has psychological and physiological expressions. Psychological expression of grief includes feelings of sadness, anger, guilt, numbness, cognitive distortion, difficulty concentrating, denial, disbelief and sometimes hallucinations such as hearing and seeing the deceased (Fischer et al., 2020; Herberman Mash et al., 2013; Love, 2007; Shear, 2011). Physiological expression includes insomnia, fatigue, heart palpitations, and physical pain (Pohlkamp et al., 2019; Stroebe et al., 2007). Approximately 10-15\% of bereaved individuals suffer persistent problems (Bonanno \& Kaltmann, 2001). Yearning for the deceased could occur for about 16 months or so after the death of a loved one (Epstein et al., 2006). Mourning is often used interchangeably with grief (Stroebe et al., 2001) but is actually the outward (behavioral) expression of the grief, such as crying, reminiscing, and introspection felt after a loss (Stroebe et al., 2001; Wolfelt, 2003).

When left unattended, grief becomes complicated grief (Herberman Mash et al., 2013), which could have a long-lasting effect on the bereaved (Neimeyer \& Sands, 2011). Complicated grief is an inability to regain stable, emotional wellbeing and deviates from the typical length of grief expected after losing a loved one (Shear, 2008; Stroebe et al., 2001). Balk (2011b) described these bereaved individuals as someone with "trouble acknowledging the death, feel 
Understanding Bereavement among College Students: Implications for Practice and Research

extremely lonely and empty, are emotionally isolated from others, find life without meaning, and feel helpless" (p.8). Other difficulties include struggles with intrusive thoughts and images, being overwhelmed by intense emotions, and going to extremes to avoid reminders of the loved one (Balk, 2011b; Shear \& Mulhare, 2008; Shear et al., 2011). Prigerson et al. (1995) suggested that complicated grief may stem from unresolved or unidentified issues bereaved individuals have with the deceased, which could lead to their trouble accepting the death or thought fixations for a prolonged period. In short, the psychological distress associated with complicated grief is persistent, pervasive, debilitating and impairs daily functioning (Shear et al., 2011).

Disenfranchised grief is due to a loss outside of the general and accepted definition of bereavement; for example, a romantic breakup, parental divorce, losing a pet, or the death of a celebrity (Doka, 2002; Micsky, 2020; Piazza-Bonin et al., 2015). Other types of disenfranchised grief may include a loss of mobility due to natural or public health crises such as the Covid-19 pandemic, civil unrest (Doka, 2002; Micsky, 2020; Piazza-Bonin et al., 2015), losing a loved one through suicide, homicide, or incarceration (Dutil, 2019). This type of loss is often perceived as non-normative, self-induced, or socially unsanctioned (Balk et al., 2011). As a result, social and emotional support for disenfranchised grief is not always provided (Thornton et al., 2007). Although disenfranchised grief is often unacknowledged, viewed as unnecessary, unacceptable, socially invalidated, or discouraged, its impact on a bereaved individual is similar to that experienced following a loss through death (Robak \& Weitzman, 1995). For example, anger, disbelief, and sadness are common emotional responses associated with disenfranchised grief (Burke \& Neimeyer, 2012; McDevitt-Murphy et al., 2012). Since disenfranchised grief is socially unsanctioned (Balk et al., 2011), individuals struggling with disenfranchised grief often feel invalidated. The lack of acknowledgment could be toward the type of relationship (e.g., 
colleagues, roommates) lost or the object of loss (e.g., pet, loss due to homicide) (Doka, 2002). The lack of support and understanding toward disenfranchised grief could make it difficult for individuals to cope with the demands of higher education and the bereavement process (Micsky, 2020).

\section{Bereavement in College Students}

\section{Types of Loss and Causes}

Family death was the most reported type of loss. Between $30 \%$ and $44 \%$ of college students reported having lost a loved one within the previous two years (Balk, 1997; Balk et al., 2010; Cousins et al., 2017; Cox et al., 2015). College students typically lose a first-degree family member such as parents, stepparents, siblings, followed by second-degree family such as grandparents, aunts, uncles, or cousins. Along with losing family members, the loss of a close friend (about 27\% within the previous two years) is also prevalent (Balk, 1997; Cox et al., 2015).

For family deaths, students identified illness as the primary cause of death, followed by auto accidents, not known, suicide, old age, murder, surgery complications, and military service (Balk, 1997; Cox et al., 2015). For the loss of a close friend, the cause of death was primarily listed as car accidents, illness (mainly cancer), suicides, and murder (Balk, 1997; Turner et al., 2013).

\section{Effect of Bereavement on College Students}

Experiencing a loss could be intense and alarming for some college students. Numerous studies on bereavement and grief have provided evidence for the negative impact of loss on students' academic performance, psychological and physical health. Disbelief is typically the first intense psychological experience following a loss. After this, yearning was the most frequently 
Understanding Bereavement among College Students: Implications for Practice and Research

reported negative psychological response. Over time, anger may set in, depression may follow soon after anger (Maciejweski et al., 2007).

\section{Impact on Identity and Daily Functioning}

Taking into consideration traditional college student's developmental trajectory:

College students who are grieving can find their identity formation challenged as they seriously question their own competence and self-worth. Individuals may experience considerable difficulty recovering from grief and thereby endanger the prospects of gaining the maturity needed to lead lives filled with a sense of autonomy, direction, and intimacy (Balk, 2001, p. 69).

Developmentally, college-aged students may not be well equipped to cope with loss, and college and university environments are not conducive for recovery after a loss (Balk, 2001; Liew \& Servaty-Seib, 2018). Balk (2011a) and Cupit et al. (2016) explained how bereavement could interfere with student identity development - What could be a time to plan, develop relationships, solidify one's identity, and learn to live independently becomes complicated when the student must deal with a loss. The loss of a parent, for example, at a time when first-year students begin to separate from their parents (Bowlby, 1980), could lead to feelings of guilt as the student strives for autonomy and independence (Servaty-Seib \& Taub, 2010). Feelings of loneliness and self-solation are already common with first-year students and can be intensified with grief (Balk et al., 1993; Servaty-Seib \& Taub, 2010. Balk (2001) also identified how a loss could reduce the bereaved's self-confidence and contribute to the feelings of lack of control, anxiety, fear, and insecurities in navigating an unpredictable world. Bonanno and Kaltman (2001) explained that within the first few months after a loss, the bereaved experience difficulties making sense of loss. These difficulties contribute to struggles with their sense of identity. Some 
Understanding Bereavement among College Students: Implications for Practice and Research

bereaved experience a sense of lost identity, expressing that they felt a part of them had gone along with the deceased. Other individuals might experience identity merging, where the bereaved felt like they were becoming more like the deceased.

Not all individuals who deal with a loss struggle with cognitive functioning, but for those who do, they experience intense symptoms, including a sense of confusion and preoccupation with the death, depersonalization, disorganization, difficulty concentrating, intrusive thoughts of deceased, and seeing them in public (Balk, 1997; Bonanno \& Kaltmann, 2001; Maciejweski et al., 2007). Besides impaired cognitive functioning, grief could also disrupt students' functioning in the emotional, physical, professional, and social realms. For example, bereaved students may experience a myriad of emotions such as anguish, numbness, loneliness, guilt, fear, and anger (Balk, 2008; Balk, 2011a; Love, 2007). The physical effects include reduced energy, shortness of breath, heart palpitations, susceptibility to getting sick, insomnia, appetite changes, and digestive issues (Bonanno, 2001; Neimeyer et al., 2008).

Disruptions in social functioning are experienced by the bereaved after the first few months of a loss, most commonly through social withdrawal and isolation or an inability to meet typical social expectations. Behaviorally, bereaved students may display restlessness, agitation, unexplained outbursts without warning (Balk, 2008; Balk, 2011b). Interpersonally, bereaved students may struggle with difficulty communicating with those who do not seem to understand or want to know what they are going through. The bereaved may become less emotionally available to their family and peers, leading to further social withdrawal and isolation (Bonanno \& Kaltman, 2001). The intensity and duration of the bereavement process can be difficult for others to handle. Research found that the non-bereaved may feel less compassion for those with high expressed emotion. The stronger the feeling of loss, and the more the bereaved conveyed 
Understanding Bereavement among College Students: Implications for Practice and Research

their sadness, the more likely an observer would pull away (Bonanno \& Kaltman, 2001). Unfortunately, the lack of understanding by the non-bereaved may result in reduced social and emotional support for bereaved students during a critical time (Balk, 2008; Balk, 2011b).

\section{Impact on Academic and Professional Development}

The impaired cognitive functioning, motivation, and self-confidence associated with bereavement could negatively impact college students' academic and professional engagement, such as difficulties in completing assignments and exams, keeping appointments and routines (Bonanno \& Kaltman, 2001; de Lamber \& Williams, 2006). Servaty-Seib and Hamilton (2006) were the first to empirically investigate the effects of a significant loss on college students' academic performance. They reported that bereaved students had a significantly lower GPA, completed fewer academic credits, experienced more instances of probation, were at a higher risk of taking an incomplete grade, withdrawing from classes, or completely dropping out compared to their non-bereaved counterparts. Similar studies on bereavement among college students supported these results. Researchers reported that bereaved undergraduate students struggle with taking exams or staying engaged in lectures and need longer than usual to complete their coursework (Cousins et al., 2017; Cupit et al., 2016).

\section{Impact of Unresolved Grief}

Grief is a common emotional response during bereavement (Shear, 2012; Stroebe et al., 2001), and for most, it will resolve on its own between 6 months to one year with a return to daily functioning (Balk, 2008; Prigerson et al., 2009). But, if left unattended, grief may develop into complicated grief, a state of chronic mourning (Schnider et al., 2007), and overwhelming experience of a loss for more than one year after the loss (Bonanno et al., 2002; Schnider et al., 2007; Shear \& Mulhare, 2008). This includes a disequilibrium in functioning and difficulty 
Understanding Bereavement among College Students: Implications for Practice and Research

regaining a sense of emotional wellbeing and full acceptance of the loss (Stroebe et al., 2001).

Individuals struggle with intense emotions such as helplessness, feelings of emptiness, emotional isolation, persistent, pervasive, and debilitating distress (Balk, 2011b; Shear, 2011). Other adverse effects include rumination, feelings of guilt for not having prevented the death, and guilt for positive emotions after a loss (Shear, 2008). Combined with a decrease in hope, complicated grief predicts greater depressive and somatic symptoms (Herberman Mash et al., 2013; Salloum et al., 2019). Research suggests that between 10-21\% of bereaved students eventually develop complicated grief (Cox et al., 2015; Herberman Mash et al., 2013; Schnider et al., 2007).

\section{Impact of Disenfranchised Grief}

As aforementioned, disenfranchised grief is bereavement outside the general and accepted definition, such as grieving the loss of a romantic relationship, loss of a pet, loss of a job, incarceration, or loss through suicide (Doka, 2002). Although this type of grief is viewed as unnecessary, socially invalidated, unacknowledged, or discouraged (Doka, 2002; Piazza-Bonin et al., 2015), adverse mental health outcomes associated with disenfranchised grief-especially those related to loss through homicide or suicide — may be just as prevalent (Burke \& Neimeyer, 2012; McDevitt-Murphy et al., 2012) and debilitating (Prigerson et al., 2009; Shear et al., 2011).

Disenfranchised grief has not been adequately studied in higher education, possibly because of the stigmatization of openly discussing and seeking professional help for this type of grief (Doka, 2002; Micsky, 2020; Piazza-Bonin et al., 2015). However, the recent coronavirus (COVID-19) pandemic has brought an incalculable loss through deaths and disruptions to socioeconomic stability. Besides the pandemic, increased incidents of anti-Asian harassment, senseless violence against people of color, and the riot and attack on the United States Congress could intensify the extent and effect of disenfranchised grief. These events, altogether, call for a 
Understanding Bereavement among College Students: Implications for Practice and Research

better understanding of and response to help college students cope with disenfranchised grief in a higher education context.

\section{Theoretical Models Related to Bereavement and Coping}

\section{Theories about Coping, Processes, Relevance, and Limitations}

Coping refers to a process of attempts to reduce or minimize the impact of perceived stressful events, often by using cognitive and behavioral strategies (Folkman et al., 1986). When faced with loss, individuals engage in either adaptive or maladaptive coping methods. Adaptive coping includes leaning on supportive friends, keeping busy, talking about the loss, accepting the loss, and turning to family for support (Cousins et al., 2017; Rask et al., 2002). Maladaptive coping methods, such as avoidance and substance use (Eddinger et al., 2019; Walker \& Shaffer, 2007) may hinder the grieving processing, exacerbate difficulties, and lead to complicated grief (Schnider et al., 2007).

Numerous models have attempted to explain the process, experience, and coping of bereavement. Developed initially to discuss the process of bereavement experienced by a surviving spouse, the Dual Process Model (DPM) by Stroebe and Schut (1999) attempts to explain the stressful duality of grieving the loss of a loved one and dealing with daily demands. The DMP suggests two categories of stressors associated with bereavement (Stroebe \& Schut, 2010). The first, loss-oriented, includes grieving the loss of the loved one and includes thoughts surrounding the death, as well as rumination and yearning for the loved one. This grief is painful as it forces the bereaved to focus on and try to make sense of the loss. The second, restorationoriented, also viewed as an important part of grieving, includes struggles of focusing on life without the loved one and maneuvering through life without their loved one. Both categories have the bereaved feeling levels of distress and anxiety as they experience the stressors of 
Understanding Bereavement among College Students: Implications for Practice and Research

bereavement. The DPM is a dynamic process that identifies how balancing grieving and daily responsibilities are necessary to deal with grief. The ability to oscillate between rumination and yearning for the loved one (loss-orientation) and focusing on current circumstances and distractions from the loss (restoration-orientation) lead to better coping and, therefore, an ability to complete tasks and other responsibilities while in bereavement (Stroebe \& Schut, 2010).

Richardson (2010) provided a synopsis of how the DPM was tested, including DPMinterventions and interventions for complicated grief using DPM principles. Although the DPM was encouraged to be applied broadly (Stroebe \& Schut, 1999; Stroebe \& Schut, 2010), our review of the literature revealed limited testing of the DPM with bereaved university students. Studies in college student bereavement identify struggles with academics (Cousins et al., 2017; Cupit et al., 2016), disruption in social functioning, and behaviors such as restlessness and agitation (Balk, 2008; Balk, 2011b). Emotional anguish such as numbness, loneliness, guilt, fear, and anger have also been studied as impactful to university students (Balk, 2008; Balk, 2011a; Love, 2007). Unresolved grief may turn into complicated grief, leading to maladaptive reactions to loss, such as extreme reactions to loss, including isolation, avoidance, and difficulty accepting the loss (Stroebe \& Schut, 2010; Thimm \& Holland, 2017). Interventions could then be customized to help students change maladaptive patterns of grief and come to terms with the loss (Stroebe \& Schut, 2010).

Bowlby's (1980) attachment theory explains how emotional bonds contribute to bereavement outcomes and continues to impact understanding bereavement (Stroebe \& Schut, 1999). Attachment theory describes the bond developed in the early years of life between a child and caregiver. When faced with stressful situations, with a developed secure attachment, dependents seek comfort and reassurance from their caregiver. A strong bond with a caregiver 
Understanding Bereavement among College Students: Implications for Practice and Research

translates to secure attachment in future and adult relationships (Bowlby, 1980). Bowlby (1980) addressed the importance of working through one's grief to eventually accept the death, leading to better adjustment after a loss. The ability to process through grief includes realizing the need to release the bonds between the bereaved and the deceased is conducted through four phases (Bowlby, 1980). The phases are a) feelings of disbelief and an overall feeling of numbness, which last from moments after hearing about the death to up to a week; b) feelings of yearning and searching followed by restlessness, crying, and seeing and expecting the deceased to come through the door; c) disorganization and despair are next, and the bereaved may feel their life unraveling since the attachment bond is no longer present. Finally, there is some disorganization remaining, even after the reality of the death comes into focus. Still, the bereaved take steps towards a life without the deceased, including building a new self-identity (Bowlby, 1980). College students tend to depend on their caregivers for emotional and practical support. When faced with the loss of the caregiver, dealing with the loss could be difficult since the source of their comfort is no longer available. Students who lose close friends and relationships also struggle because a source of support is no longer available. It is necessary to understand the impact of bereavement on undergraduate students as losing someone close affects a student's life. Based on a review of the literature, attachment theory related to bereavement has not been further studied in undergraduate students. The bonds students have with their caregivers, friends, and close relationships require further study in the impact of bereavement.

Lazarus and Folkman's (1984) model of cognitive appraisal addresses the interaction between the stressors produced by the environment and reactions because the stressors contributed to the development of the dual process model by Stroebe and Schut (1999). Cognitive appraisal is the process of when faced with a stressor. There is an emotional reaction 
Understanding Bereavement among College Students: Implications for Practice and Research

that leads to the interpretation of the stressors, which then contributes to the behavioral response for dealing with the stressors (Lazarus \& Folkman, 1984). For example, receiving a phone message from a loved one saying they have something important to discuss. Before returning the phone call, we would think about who the caller was, their tone of voice, and hypothesize what the important information could be. We determine, or reappraise, the situation has nothing to do with us and must be about something else. The model of cognitive appraisal leads to coping techniques or methods used by the bereaved to reduce or minimize the impact of the loss and to overcome the stress and grief associated with a loss (Folkman et al., 1986). Two types of coping techniques or methods include emotion-focused coping (adaptive) and problem-focused coping (maladaptive). Emotion-focused coping, which requires the bereaved to regulate their emotions related to the loss, constitutes two sub-types: active-emotion coping, such as talking through the death, and avoidant emotional coping, such as using distraction to avoid dealing with the loss (Folkman \& Lazarus, 1985; Folkman et al., 1986; Holahan \& Moos, 1987; Lazarus \& Folkman, 1984). Problem-focused coping requires the bereaved to actively overcome a distressing situation, such as analyzing the problem to make sense of it or developing a plan and working through it (Folkman \& Lazarus, 1985; Lazarus \& Folkman, 1984).

When faced with stressful stimuli (losses), Lazarus and Folkman's (1984) model proposes that individuals use two appraisal levels to determine their method of coping. The primary appraisal determines the threat of the stimuli, whereas the secondary appraisal determines available resources, such as inner strength and social support for coping with the threat. Suppose the bereaved individuals determine that the threat exceeds their resources to cope. In that case, they tend to use (active or avoidant) emotion-focused coping techniques, including taking anger out on others. On the other hand, if the bereaved individuals determine that they have sufficient 
Understanding Bereavement among College Students: Implications for Practice and Research

resources to cope with the loss despite its high impact, they are more likely to use problemfocused coping techniques, such as trying to make sense of the problem, which may lead to better adjustment. Students who approach bereavement with an emotion-focused coping strategy (e.g., withdrawal and isolation) may have difficulty balancing grief with academics and other responsibilities. Those who utilize problem-focused coping techniques (e.g., reaching out to their professor for accommodations) tend to have the problem-solving ability and external resources to navigate their grief. Previous studies using the cognitive appraisal model with undergraduates have focused on gender differences in coping and perceived control in academic subjects (Amin et al., 2019). After a search of the literature, limited study into cognitive appraisal of bereaved undergraduate students has been conducted.

Finally, we considered the five stages of grief developed by Kubler-Ross (1969). Initially developed as a five-stage approach (denial, anger, bargaining, depression, and acceptance) to explain how terminally ill individuals deal with their own impending death, Kubler-Ross has been adapted to explain grief responses in bereaved individuals. To date, several other alternatives to this staged approach have been offered that take bereavement from a linear process to one that is more interactive between the individuals and their environments (Harvard Mental Health Letter, 2011). Based on our literature review, the Kubler-Ross five-stage approach to grief does not have empirical support to show its effectiveness in working through grief in any domain of grief counseling.

\section{Ethnic-Cultural and Gender Differences in Bereavement}

\section{Ethnic-Cultural Differences}

Grief is a common, shared, and universal experience. However, culture-specific experiences influence the expression and coping with grief, making it essential to understand grief and bereavement from a cultural context (Moore et al., 2020; Oltjenbruns, 1998; Schoulte, 
Understanding Bereavement among College Students: Implications for Practice and Research

2011). In the United States, a distressing similarity of grief experiences among people of color involves loss through homicide. African American/Black and Latinx communities have higher rates of violent deaths than Whites (Kochanek et al., 2019; Morgan \& Truman, 2020). The Black and Latinx communities tend to experience intense grief after a loss, especially if the loss is unexpected or caused by homicides (Rosenblatt \& Wallace, 2013; Schoulte, 2011; Sharpe et al., 2013). The loss of a loved one due to homicide also increases the bereaved individuals' likelihood of developing anxiety, complicated grief, and posttraumatic stress disorders (McDevitt-Murphy et al., 2012).

Some studies have shown that South Asians and African Americans similarly display feelings of hopelessness, anger, difficulty concentrating, and a yearning for the deceased (Inman et al., 2007; Neimeyer et al., 2003; Laurie \& Neimeyer, 2008). Whereas South Asians, Chinese, and Latinx tend to express more explicit emotions, such as crying, than Whites (Inman et al., 2007; Neimeyer et al., 2003; Oltjenbruns, 1998). Chinese individuals may also exhibit higher death-related anxiety levels and are more superstitious than Whites or other ethnic minorities (Neimeyer et al., 2003; Wong, 2012). Superstition requires behaviors and beliefs that function within the realm of supernatural forces (Corsini, 2002). For example, specific dates have more negative or positive meanings than others, and speaking of death will bring bad luck (Mok et al., 2002).

In terms of coping styles, individualistic cultures embrace the independence and autonomy of individuals within the family unit. In contrast, collectivist cultures emphasize interdependence, seeing the individual as a necessary part of the entire family unit (Ross \& Wang, 2010). Relying on family support (relational coping) and continuing a close relationship with the deceased by reliving their memories, looking at their pictures, or watching their videos 
Understanding Bereavement among College Students: Implications for Practice and Research

are common in African American, Asian, and Latinx communities (Barnes, 2006; Boulware \& Bui, 2016; Inman et al., 2007; Lalande \& Bonanno, 2006; Moore et al., 2020; Schoulte, 2011; Yu et al., 2016). Research has supported the adaptive and effective role of familial support in overcoming grief. For instance, Boulware and Bui (2016) identified that greater levels of social support in the African American community help reduce the instances of prolonged grief. Besides relational coping, religious and spiritual coping, such as leaning on immediate family members, prayer, and increase in faith, are also commonly used by African Americans, South Asian, and Latinx (Boulware \& Bui, 2016; Inman et al., 2007; Moore et al., 2020; Schoulte, 2011; Sharpe \& Boyas, 2011). By contrast, research has established that members from minoritized groups are less likely than Whites to seek professional psychological help to cope with their losses (Inman et al., 2007; Laurie \& Neimeyer, 2008). This may be because they are more inclined to first seek help from their families or communities because of a deep sense of collective attachment (Zamudio et al., 2020).

\section{Gender Differences}

Gender differences in bereavement are prevalent in cultural expectations of how males and females should behave while bereaved. Gender differences also influence the coping process of bereavement (Lindstrom, 1999). However, there are instances where components of bereavements do not show gender differences (Lawrence et al., 2006). Walker et al. (2011) found male and female undergraduate students experienced similar difficulties with increased mental health problems and social behavior changes the closer they are to the deceased. Talking about a loss is a similar experience for both males and females (Stelzer et al., 2019). 
Understanding Bereavement among College Students: Implications for Practice and Research

Females are considered more interpersonal and better at emotional expression than males, seek others for support, and are encouraged to express their emotions more often than males (Martin \& Doka, 2000; Stelzer et al., 2019). Nevertheless, females are at a higher risk of developing depression and anxiety (Little et al., 2009) and report more mental health problems than males (Walker et al., 2011). Males are socialized not to express their emotions (Martin \& Doka, 2000). Males engage in a more problem-solving method, thinking more about the loss than feeling the loss. Minimizing negative emotions may help males in their grief (Lawrence et al., 2006). Instead, males may exhibit behavioral outbursts than females (Kraatz Keiley et al., 2000). Intrusive thoughts are not related to gender differences (Little et al., 2009). Gender differences are not found on measures of psychological distress (i.e., hopelessness, depression, suicidal ideation, and death anxiety) or coping strategies (Lawrence et al., 2006). More research is needed to understand gender differences in college student bereavement (Lawrence et al., 2006).

\section{Current Intervention}

Colleges and universities have a mixed approach to bereavement support, which includes structured support programs, links for university-related resources, links for external resources, or support provided by campus counseling centers (Valentine \& Woodthorpe, 2020). Structured support, such as a clinical intervention that is geared toward helping college students process through their grief and regain equilibrium, has been shown effective. For example, Battle and colleagues (2013) developed a model for supporting bereaved students. The support program, titled Reflect, consisted of structured bereavement support groups, informal drop-in workshops, and supplemental resources related to coping with loss. Participant feedback identified the group support elements, meeting other students like them, and being in a comfortable environment as 
Understanding Bereavement among College Students: Implications for Practice and Research

helpful. Participants even recommended adding more meeting sessions as an improvement to the process. Prior (2015), a licensed independent social worker and faculty member at Wellesley College used a structured grief group approach to establish trust with bereaved undergraduates. Using three conversational formats: soliloquy, monologue, and dialogue, the support group helped students articulate their grief experiences and form the ability to relate to one another. Each new academic year, students provide their grief soliloquy or personal grief stories. Then, meeting weekly, students engage in monologues, an opportunity to discuss daily experiences, such as challenges and heartbreaks, with their ongoing grief. From there, students engage in dialogue, meant to allow unscripted, open exchange conversation. Students build their "grief voice" (Prior, 2015; p. 117), an ability to gain a sense of belongingness, reduce isolation and loneliness, and provide a safe space to discuss feelings of guilt related to a loss.

Collaborations with agencies, such as local hospice offices, have also been used to support undergraduate students. O'Neill and Fry (2013), a licensed clinical psychologist and counselor, used a hospice curriculum of activities and topics to support undergraduate students through their grief. Symbolic activities, such as artistic expression of their grief, were also used. Participants in the collaborative grief support group expressed appreciation for opportunities to grieve and accept the loss. There is limited research into the implementation and effectiveness of bereavement support programs in higher education. What colleges and universities have available does not always support students' needs, such as social and cultural context or the impact of grief

(Valentine \& Woodthorpe, 2020).

Academic programs and policies on campus also play a critical role in supporting bereaved students to maintain their academic goals. For example, the Grief Absence Policy for Students (GAPS; Servaty-Seib \& Liew, 2019) developed at Purdue University provides a support 
Understanding Bereavement among College Students: Implications for Practice and Research

system between the bereaved student and the faculty and staff. Accommodations are then provided to the student to ensure completion of missed assignments and missed attendance due to funerals. Social support organizations work with universities and colleges, providing numerous support options (Prior, 2015). Actively Moving Forward (AMF) offers chapters throughout the United States. Each chapter offers in-person support groups, virtual support groups, information on self-care, and how to help those grieving, including the convenience of a smartphone app. Based on our search, Utah State University, the University of Louisiana at Lafayette, and Boston University are a few that provide information about the AMF chapter and how students can take part in AMF.

We have reviewed the literature for common therapeutic counseling skills or modalities used in college counseling services. Besides support groups (Battle et al., 2013; Prior, 2015; Valentine \& Woodthorpe, 2020), to date, limited attention has been given to the techniques and modalities for bereavement support provided through college counseling centers. Ober et al. (2012) and Dodd et al. (2020) discussed the limited training counselors have received in grief therapy techniques. An important factor in the success of any bereavement intervention or support system is the counselors' training and experience in the subject. Ober et al. (2012) studied the relationship between counselor training, preparedness, and competence. They have found that training and preparedness are a strong predictor of competence and effectiveness. Licensing requirements identify graduate program must provide content in assessment and diagnosis, counseling for individuals, groups, couples and families, internship, and supervision hours. The training required to be an effective counselor is built in the graduate program and training. Dodd et al. (2020) interviewed a group of counselors, psychologists, and psychiatrists, and there was a consensus that psychoeducation of grief was an important skills area. Counselors 
Understanding Bereavement among College Students: Implications for Practice and Research

working with bereaved individuals must have training and a knowledge base in grief counseling to effectively identify coping problems and plan effective interventions (Dodd et al., 2020; Ober et al., 2012).

\section{Implications for Practice and Research}

Although we found numerous recommendations for developing support programs for bereaved students in our literature review search, we could only identify a limited number of existing programs that are currently in place or that have been evaluated. In the following, we summarize the recommendations provided by the experts and discuss how these strategies might be an effective means of support for bereaved college students. Furthermore, we discuss the implications for future practice and research.

Balk (2001) called for more university involvement in working with bereaved undergraduates to help reduce the likelihood of academic issues. He proposed a university-based bereavement support program that called for non-bereaved students' training to provide peer support. Teaching non-bereaved students how to support someone through a loss not only educates the non-bereaved but also provides adequate, peer-based support for the bereaved. Developing structured interventions and raising campus consciousness and awareness of grieving is another effective university-based support program (Balk, 2001). Research has shown that bereaved students felt misunderstood and alienated by their friends who seem not to know how to be supportive (Balk, 2008; Balk, 2011b). Encouraging bereaved students to be a part of the support system will help them access and receive needed support.

Along with peer support, colleges and universities should have policies and structures to work with bereaved college students. Balk (2008) recommended university administrators develop structured protocols for working with bereaved students. For instance, allowing 
Understanding Bereavement among College Students: Implications for Practice and Research

bereaved students to drop courses after specified deadlines is one way to reduce the punitive financial consequence for these students. Faculty training in working with bereaved students and learning effective accommodations can also help bereaved students to maintain their academic goals and stay engaged during the grief process. Often it may be best to ask the bereaved students what they would need or have needed for support if they lost a loved one. Surveying incoming freshman and transfer students about relevant life events, including the experience of having lost a loved one, could help universities prepare for ramifications associated with these life events and for identifying resources to support these incoming students (Balk, 2008).

Finally, Servaty-Seib and Liew (2019) addressed the importance of colleges and universities developing clear and effective leave of absence policies for students struggling with loss. The policy should provide a structured process for faculty and administration to help students who require accommodations because of bereavement, funerals, and life after a loss. The student-focused bereavement policy provides excused absences from classes that require attendance and participation and a fixed number of opportunities to complete missed coursework (Servaty-Seib \& Liew, 2019).

Although bereavement and grief are universal experiences shared by all, current perspectives of bereavement and grief, especially in terms of reactions to loss, coping with loss, and interventions used, tend to be dominated by a Eurocentric, individualistic-oriented worldview and experience (Moore et al., 2020). Scholars have highlighted the importance of developing or culturally adapting existing treatment and intervention to be relevant to non-White clients. Sharpe and Boyas (2011) have addressed the importance of including spiritual beliefs and practices within the clinical assessment and intervention framework, as religion and spirituality have been shown to play a dominant role in the African American and Latinx 
Understanding Bereavement among College Students: Implications for Practice and Research

community (Boulware \& Bui, 2016; Sharpe \& Boyas, 2011). Moore and colleagues (2020) recommended practitioners include non-White guest speakers during support group meetings to help facilitate a sense of belonging among participants of color.

In terms of research, we noted several limitations that could be addressed in future studies. First, previous studies have provided evidence of the acceptability of bereavement support programs (Balk, 2001; Battle et al., 2013). Participants' feedback was positive and suggested a need for this type of program. However, empirical support demonstrating the efficacy of such programs is lacking. Longitudinal studies are also needed to understand if interventions can provide relief and prevent long-term effects of bereavement, including depression and suicidal ideation (Battle et al., 2013).

Second, college students who identify as BIPOC are underrepresented in current bereavement research and intervention studies. Future studies should attempt to recruit participants from historically underrepresented backgrounds, including but not limited to students who identify as non-White, gender diverse, low-income, first-generation, or immigrants (Moore et al., 2020; Neimeyer et al., 2008). This will provide researchers and practitioners an opportunity to develop a better understanding of the full spectrum of bereavement experiences among college students.

\section{Conclusion}

The loss of a significant person to death is disruptive and contributes to disequilibrium in functioning. Disenfranchised losses are also impactful and present the same obstacles and issues like the death of a loved one (Doka, 2002; Piazza-Bonin et al., 2015). University-based bereavement programs and strategies provide faculty, staff, and students with the tools necessary to help the bereaved cope with their loss (Battle et al., 2013; Doka, 2002; Piazza-Bonin et al., 
Understanding Bereavement among College Students: Implications for Practice and Research

2015). Loss is also more than losing someone through death. Any loss-type experience can bring on grief experience, which presents similar obstacles as typical bereavement (Doka, 2002;

Piazza-Bonin et al., 2015). Universities must invest in professional development training in bereavement support for faculty and staff and provide culturally responsive bereavement interventions focusing on support groups, workshops, and supplemental information (Balk, 2001; Balk, 2008; Battle et al., 2013). With the loss of lives and significant disruptions to normalcy due to the recent global coronavirus pandemic, college students could experience a tremendous amount of stress and grief on multiple levels. Counseling and health center, residence life, ministry office (for faith-based institutions), or faculty may be the first stop many incoming firstyear or returning students turn to for support and resources. Thus, outreach and support programs, policies, and protocols should be in place to ensure students who have recently gone through a grief process would stay engaged and continue to thrive.

\section{References}

Amin, R., Asadullah, M. A., \& Sultan, S. (2019). Perceived stress and coping strategies among undergraduate university students: Role of gender. Bahria Journal of Professional Psychology, 18(1), 63-76. https://bjpp.bahria.edu.pk/index.php/BJPP/article/view/120

Balk, D. E. (1997). Death, bereavement and college students: A descriptive analysis. Mortality, 2(3), 207-220. https://doi.org/10.1080/713685866

Balk, D. E. (2001). College student bereavement, scholarship, and the university: A call for university engagement. Death Studies, 25, 67-84. http://dx.doi.org/10.1080/07481180126146

Balk, D. E. (2008). Grieving: 22 to 30 percent of all college students. New Directions for Student Services, Special Issue Assisting Bereaved College Students, 121, 5-14. http://dx.doi.org/10.1002/ss.262 
Understanding Bereavement among College Students: Implications for Practice and Research

Balk, D. E. (2011a). Adolescent development and bereavement: An introduction. The Prevention Researcher, 18(3), 3-9.

\section{https://link.gale.com/apps/doc/A273786623/AONE? $\mathrm{u}=$ anon $~ 734 f 1 \mathrm{a} 5 \mathrm{c} \&$ sid=googleSchol}

\section{$\underline{\operatorname{ar} \& x i d=e e 2926 c 9}$}

Balk, D. E. (2011b). Helping the bereaved college student. Springer.

Balk, D. E., Tyson-Rawson, K., \& Colletti-Wetzel, J. (1993). Social support as an intervention with bereaved college students. Death Studies, 17, 427-450. https://doi.org/10.1080/07481189308253387

Balk, D. E., Walker, A. C., \& Baker, A. (2010). Prevalence and severity of college student bereavement examined in a randomly selected sample. Death Studies, 34, 459-468. http://dx.doi.org/10.1080/07481180903251810

Balk, D. E., Zaengle, D., \& Corr, C. A. (2011). Strengthening grief support for adolescents coping with a peer's death. School Psychology International, 32(2), 144-162.

\section{https://doi.org/10.1177/0143034311400826}

Barnes, D. H. (2006). The aftermath of suicide among African Americans. Journal of Black Psychology, 32(3), 335-348. http://dx.doi.org/10.1177/0095798406290470

Battle, C. L., Greer, J. A., Ortiz-Hernandez, S., \& Todd, D. M. (2013). Developing and implementing a bereavement support program for college students. Death Studies, 37, 362-382. http://dx.doi.org/10.1080/07481187.2011.634087

Bonanno, G. A. (2001). The crucial importance of empirical evidence in the development of bereavement theory: Reply to Archer (2001). Psychological Bulletin, 127(4), 561564.https://doi.org/10.1037/0033-2909.127.4.561

Bonanno, C. A., \& Kaltman, S. (2001). The varieties of grief experience. Clinical Psychology Review, 21, 705-734. http://dx.doi.org/10.1016/S0272-7358(00)00062-3 
Understanding Bereavement among College Students: Implications for Practice and Research

Bonanno, G. A., Wortman, C. B., Lehman, D. R., Tweed, R. G., Sonnega, J., Carr, D., \& Nesse, R. M. (2002). Resilience to loss and chronic grief: A prospective study from preloss to 18- months postloss. Journal of Personality and Social Psychology, 83(5), 1150-1164. http://dx.doi.org/10.1037//0022-3514.83.5.1150

Boulware, D. L, \& Bui, N. H. (2016). Bereaved African American adults: The role of social support, religious coping, and continuing bonds. Journal of Loss and Trauma, 21(3), 192202. https://doi.org/10.1080/15325024.2015.1057455

Bowlby, J. (1980). Attachment and loss: Volume 3. Loss - sadness and depression. Basic Books. Burke, L. A., \& Neimeyer, R. A. (2012). Prospective risk factors for complicated grief. In M. S. Stroebe, H. Schut, J. van der Bout \& P. Boelen (Eds.), Complicated grief (pp.145-161). Routledge.

Bustamante, J. (2019). College dropout rates. https://educationdata.org/college-dropout-rates Corsini, R. J. (2002). Dictionary of psychology. Brunner/Mazel.

Cousins, C., Servaty-Seib, H. L., \& Lockman, J. (2017). College student adjustment and coping: Bereaved and non-bereaved students. OMEGA - Journal of Death and Dying, 74(4), 386- 409. http://dx.doi.org/10.1177/0030222815598911

Cox, B., Dean, J. G., \& Kowalski, R. M. (2015). Hidden trauma, quiet drama: the prominence and consequences of complicated grief among college students. Journal of College Student Development, 56(3), 280-285. http://dx.doi.org/10.1353/csd.2015.0030

Cupit, I. N., Servaty-Seib, H. L., Parikh, S. T., Walker, A. C., \& Martin, R. (2016). College and the grieving student: A mixed-method analysis. Death Studies, 40(8), 494-506. http://dx.doi.org/10.1080/07481187.2016.1181687 
Understanding Bereavement among College Students: Implications for Practice and Research

de Lambert, K., \& Williams, T. (2006). In sickness and in need: The how and why of special consideration for students. Assessment \& Evaluation in Higher Education, 31(1), 55-69. https://dx.doi.org/10.1080/02602930500350182

Dodd, A., Guerin, S., Delany, S., \& Dodd, P. (2020). Complicated grief knowledge, attitudes, skills, and training among mental health professionals: A qualitative exploration. Death Studies. https://doi.org/10.1080/07481187.2020.1741048

Doka, K. J. (2002) Disenfranchised grief. In K. J. Doka (Ed.). Disenfranchised grief. Author. Dutil, S. (2019). Adolescent traumatic and disenfranchised grief: Adapting an evidence-based intervention for Black and Latinx youths in schools. Children \& Schools, 41(3), 179-187. https://doi.org/10.1093/cs/cdz009

Eddinger, J. R., Humiston, T. M., Sutton, M. L., Jobe-Shields, L., \& Williams, J. L. (2019). Alcohol use and drinking motives among suddenly bereaved college students. Journal of Dual Diagnosis, 15(1), 16-24. http://doi.org/10.1080/15504263.2018.1531185

Epstein, R., Kalus, C., \& Berger, M. (2006). The continuing bond of the bereaved towards the deceased and adjustment of loss. Mortality, 11, 253-269. http://dx.doi.org/10.1111/j.1475-6811.2011.01352.x

Folkman, S., \& Lazarus, R. S. (1985). If it changes it must be a process: Study of emotion and coping during three stages of a college examination. Journal of Personality and Social Psychology, 48(1), 150-170. https://doi.org/10.1037/0022-3514.48.1.150

Folkman, S., Lazarus, R. S., Gruen, R. J., \& DeLongis, A. (1986). Appraisal, coping, health status, and psychological symptoms. Journal of Personality and Social Psychology, 50(3), 571-579. http://dx.doi.org.ezp.lib.cwu.edu/10.1037/0022-3514.50.3.571

Harvard Medical Health Letter. (2011). Beyond the five stages of grief. https://pubmed.ncbi.nlm.nih.gov/22408814/ 
Understanding Bereavement among College Students: Implications for Practice and Research

Herberman Mash, H. F., Fullerton, C. D., \& Ursano, R. J. (2013). Complicated grief and bereavement in young adults following close friend and sibling loss. Depression and Anxiety, 30, 1202-1210. http://doi.org/10.1002/da.22068

Holahan, C. J., \& Moos, R. H. (1987). Personal and contextual determinants of coping strategies. Journal of Personality and Social Psychology, 52(5), 946-955. http://psycnet.apa.org/buy/1987-25245-001

Inman, A. G., Yeh, C. J., Madan-Bahel, A., \& Nath, S. (2007). Bereavement and coping of South Asian families post 9/11. Journal of Multicultural Counseling and Development, 35, 101115. http://dx.doi.org/10.1002/j.2161-1912.2007.tb00053.x

Kochanek, K. D., Murphy, S. L., Xu, J., \& Arias, E. (2019). Deaths: Final data for 2017. National Vital Statistics Reports: US Department of Health and Human Services, 68(9), 1-76. https://www.cdc.gov/nchs/data/nvsr/nvsr68/nvsr68_09-508.pdf

Kraatz Keiley, M., Bates, J. E., \& Dodge, K. A. (2000). A cross-domain growth analysis: Externalizing and internalizing behaviors during 8 years of childhood. Journal of Abnormal Child Psychology, 28(2), 161-179. http://dx.doi.org/10.1023/a:1005122814723

Kubler-Ross, R. (1969). On death and dying. Macmillan.

Lalande, K. M., \& Bonanno, G. A. (2006). Culture and continuing bonds: A prospective comparison of bereavement in the United States and the People's Republic of China. Death Studies, 30, 303-325. https://doi.org/10.1080/07481180500544708

Laurie, A., \& Neimeyer, R. A. (2008). African American in bereavement: Grief as a function of ethnicity. OMEGA - Journal of Death and Dying, 57(2), 173-193. https://doi.org/10.2190/OM.57.2.d 
Understanding Bereavement among College Students: Implications for Practice and Research

Lawrence, E., Jeglic, E. L., Matthews, L. T., \& Pepper, C. M. (2006). Gender differences in grief reactions following the death of a parent. OMEGA - Journal of Death and Dying, 52(4), 323-337. https://doi.org/10.2190/55WN-1VUF-TQ3W-GD53

Lazarus, R. S., \& Folkman, S. (1984). Stress, appraisal, and coping. Springer Publishing Company.

Liew, C. H., \& Servaty-seib, H. L. (2018). College student grief, grief differences, family communication, and family satisfaction. Death Studies, 42(4). https://doi.org/10.1080/07481187.2017.1334014

Lindstrom, T. C. (1999). Coping with bereavement in relation to different feminine gender roles. Scandinavian Journal of Psychology, 40(1), 33-41. http://dx.doi.org.ezp.lib.cwu.edu/10.1111/1467-9450.00095

Little, M., Sandler, I. N., Wolchik, S. A., Tein, J. Y., \& Ayers, T. S. (2009). Comparing cognitive and stress mechanisms underlying gender differences in recovery from bereavement-related problems. Journal of Clinical Child \& Adolescent Psychology, 38(4), 486-500. http://dx.doi.org/10.1080/15374410902976353

Love, A. W. (2007). Progress in understanding grief, complicated grief, and caring for the bereaved. Contemporary Nurse: A Journal for the Australian Nursing Profession, 27, 7383. http://dx.doi.org/10.5172/conu.2007.27.1.73

Maciejweski, P. K., Zhang, B., Block, S. D., \& Prigerson, H. G. (2007). An empirical examination of the stage theory of grief. Journal of the American Medical Association, 297(20), 716-724. http://dx.doi.org/10.1001/jama.297.20.2200

Martin, T. L., \& Doka, K. (2000). Men don't cry, women do: Transcending gender stereotypes of grief. Brunner/Mazel. 
Understanding Bereavement among College Students: Implications for Practice and Research

McDevitt-Murphy, M. E., Neimeyer, R. A., Burke, L. A., Williams, J. L., \& Lawson, K. (2012).

The toll of traumatic loss in African American bereaved by homicide. Psychological Trauma: Theory, Practice, and Policy, 4(3), 303-311. http://dx.doi.org/10.1037/a0024911

Micsky, T. (2020). Uncertain times: Coping with loss during the COVID-19 pandemic. https://www.socialworktoday.com/archive/exc_042420.shtml

Mok, E., Lee, W. M., \& Wong, F. K. Y. (2002). The issue of death and dying: Employing problem-based leering in nursing education. Nurse Education Today, 22, 319-329. http://dx.doi.org/10.1054/nedt.2001.0708

Moore, S. E., Jones-Eversley, S. D., Tolliver, W. F., Wilson, B., \& Harmon, D. K. (2020). Cultural responses to loss and grief among Black Americans: Theory and practice implications for clinicians. Death Studies. http://dx.doi.org/10.1080/07481187.2020.1725930

Morgan, R. E., \& Truman, J. I. (2020). Criminal victimization, 2019. US Department of Justice Office of Justice Programs: Bureau of Justice Statistics. https://www.bjs.gov/content/pub/pdf/cv19.pdf

Neimeyer, R. A., Laurie, A., Mehta, T., Hardison, H., \& Currier, J. M. (2008). Lessons of loss: meaning making in bereaved college students. New Directions for Student Services, 121, 27-39. http://dx.doi.org/10.1002/ss.264

Neimeyer, R. A., Moser., R. P., \& Wittkowski, J. (2003). Assessing attitude towards dying and death: Psychometric considerations. OMEGA - Journal of Death and Dying, 47, 45-76. https://doi.org/10.2190/EP4R-TULM-W52G-L3EX 
Understanding Bereavement among College Students: Implications for Practice and Research

Neimeyer, R. A., \& Sands, D. (2011). Meaning reconstruction in bereavement. In R. A.

Neimeyer, D. L. Harris, H. R. Winokuer, \& G. F. Thornton (Eds), Grief and bereavement in contemporary society: Bridging research and practice (pp. 9-22). Routledge.

O'Neill, D., \& Fry, M. (2013). The grief group: A university and hospice collaboration. Journal of College Student Development, 54(4), 430-432. https://eric.ed.gov/?id=EJ1018012

Oltjenbruns, K. A. (1998). Ethnicity and the grief response: Mexican American versus Anglo American college students. Death Studies, 22, 141-155.

\section{https://doi.org/10.1080/074811898201641}

Ober, A. M., Granello, D. H., \& Wheaton, J. E. (2012). Grief counseling: An investigation of counselors' training, experience, and competencies. Journal of Counseling \& Development, 90(2), 150-159. https://dx.doi.org/10.1111/j.1556-6676.2012.00020.x

Piazza-Bonin, E., Neimeyer, R. A., Burke, L. A., McDevitt-Murphy, M. E., \& Young, A. (2015). Disenfranchised grief following African American homicide loss: An inductive case study. OMEGA - Journal of Death and Dying, 70, 404427. http://dx.doi.org/10.1177/0030222815573727

Pohlkamp, L., Kreicbergs, U., \& Sveen, J. (2019). Bereaved mothers' and fathers' prolonged grief and psychological health 1 to 5 years after loss: A nationwide study. Psychooncology, 28(7), 1530-1536. http://dx.doi.org/10.1002/pon.5112

Prigerson, H. G., Frank, E., Kasl, S. V., Reynolds, C. F., Anderson, B., Zubenko, G. S., Houck, C. J., \& Kupfer, D. J. (1995). Complicated grief and bereavement-related depression as distinct disorders: Preliminary empirical validation in elderly bereaved spouses. American Journal of Psychiatry, 152, 22-30. http://dx.doi.org/10.1176/ajp.152.1.22 
Understanding Bereavement among College Students: Implications for Practice and Research

Prigerson, H. G., Horowitz, M. J., Jacobs, S. C., Parkes, C. M., Aslan, M., Goodkin, K., \& Maciejewski, P. K. (2009). Prolonged grief disorder: Psychometric validation of criteria proposed for DSM-V and ICD-11. PLoS Medicine 6, Article e1000121. http://dx.doi.org/10.1371/journal.pmed.1000121

Prior, A. (2015). A guide to setting up a college bereavement group: Using monologue, soliloquy, and dialogue. Journal of College Student Psychotherapy, 29, 111-119. https://dx.doi.org/10.1080/87568225.2015.1008366

Rask, K., Kaunonen, M., \& Paunonen-Ilmonen, M. (2002). Adolescent coping with grief after the death of a loved one. International Journal of Nursing Practice, 8, 137-142. https://onlinelibrary.wiley.com/doi/pdf/10.1046/j.1440-172X.2002.00354.X

Richardson, V. E. (2010). The dual process model of coping with bereavement: A decade later. OMEGA - Journal of Death and Dying, 61(4), 269-271.

\section{https://dx.doi.org/10.2190/OM.61.4.a}

Robak, R. W., \& Weitzman, S. P. (1995). Grieving the loss of romantic relationships in young adults: An empirical study of disenfranchised grief. OMEGA - Journal of Death and Dying,30(4), 269-281. https://dx.doi.org/10.2190/CY1W-V6RL-0L5V-G4Q2

Rosenblatt, P. C., \& Wallace, B. R. (2013). African American grief. Routledge.

Ross, M., \& Wang, Q. (2010). Why we remember and what we remember culture and autobiographical memory. Perspectives on Psychology Science, 5(4), 401-409. http://dx.doi.org/10.1177/1745691610375555

Salloum, A., Bjoerke, A., \& Johnco, C. (2019). The association of complicated grief, depression, posttraumatic growth, and hope among bereaved youth. OMEGA - Journal of Death and Dying, 79(2), 157-173. http://dx.doi.org/10.1177/0030222817719805 
Understanding Bereavement among College Students: Implications for Practice and Research

Schnider, K. R., \& Elhai, J. D., \& Gray, M. J. (2007). Coping style use predicts posttraumatic stress and complicated grief symptom severity among college students reporting a traumatic loss. Journal of Counseling Psychology, 54, 344-350.

\section{http://dx.doi.org/10.1037/0022-0167.54.3.344}

Schoulte, J. C. (2011). Bereavement among African Americans and Latino/a Americans. Journal of Mental Health Counseling, 33(1), 11-20. https://doi.org/10.17744/mehc.33.1.r4971657p7176307

Servaty-Seib, H. L., \& Hamilton, L. A. (2006). Educational performance and persistence of bereaved college students. Journal of College Student Development, 47(2), 225-234, http://dx.doi.org/10.1353/csd.2006.0024

Servaty-Seib, H. L., \& Liew, C. H. (2019). Advocating for bereavement leave policies for college students. Journal of College Student Development, 60(2), 240-244. http://dx.doi.org/10.1353/csd.2019.0021

Servaty-Seib, H. L., \& Taub, D. J. (2010). Bereavement and college students: The role of counseling psychology. The Counseling Psychologist, 38(7), 947-975. http://dx.doi.org/10.1177/0011000010366485

Sharpe, T. L., \& Boyas, J. (2011). We fall down: the African American experiences of coping with the homicide of a loved one. Journal of Black Studies, 42(6), 855-873. http://dx.doi.org/10.1177/0021934710377613

Sharpe, T. L., Joe, S., \& Taylor, K. C. (2013). Suicide and homicide bereavement among African Americans: Implications for survivor research and practice. OMEGA - Journal of Death and Dying, 66(2), 153-172. http://dx.doi.org/10.2190/om.66.2.d.

Shear, M. K., (2008). Complicated grief. Psychiatric Annals, 38(10), 662-670. http://dx.doi.org/10.3928/00485713-20081001-10 
Understanding Bereavement among College Students: Implications for Practice and Research

Shear, M. K. (2011). Bereavement and the DSM5. OMEGA - Journal of Death and Dying, 64, 101-118. http://dx.doi.org/10.2190/OM.64.2.a

Shear, M. K. (2012). Getting straight about grief. Depression and Anxiety, 29, 461-464. http://dx.doi.org/10.1002/da.21963

Shear, M. K., \& Mulhare, E. (2008). Complicated grief. Psychiatric Annals, 38(10), 662-670. https://doi.org/10.3928/00485713-20081001-10

Shear, M. K., Simon, N., \& Wall, M., Zisook, S., Neimeyer, R., Duan, N., Reynolds, C., Lebowitz, B., Sung, S., Ghesquiere, A., Gorscak, B., Clayton, P., Ito, M., Nakajima, S., Konishi, T., Melhem, N., Meert, K., Schiff, M., O'Connor, M. F.,...Keschaviah, A. (2011). Complicated grief and related bereavement issues for DSM-5. Depression and Anxiety, 28(2), 103-117. http://dx.doi.org/10.1002/da.20780

Stelzer, E. M., Atkinson, C., O'Connor, M. F., \& Croft, A. (2019). Gender differences in grief narrative construction: A myth or reality? European Journal of Psychotraumatology, Article e1688130. http://dx.doi.org/10.1080/20008198.2019.1688130

Stroebe, M. S., Hansson, R. O., Schut, H., \& Stroebe, W. (2008). Bereavement research: contemporary perspectives. In M. S. Stroebe, R. O. Hansson, H. Schute, \& W. Stroebe (Eds.), Handbook of bereavement research and practice: Advances in theory and intervention (3-25). American Psychological Association.

Stroebe, M. S., Hansson, R. O., Stroebe, W., \& Schut, H. (2001). Introduction: concepts and issues in contemporary research on bereavement. In M. S. Stroebe, R. O. Hansson, W. Stroebe, \& H. Schut (Eds.), Handbook of bereavement research: Consequences, coping and care (pp. 3-22). American Psychological Association. 
Understanding Bereavement among College Students: Implications for Practice and Research

Stroebe, M., \& Schut, H. (1999). The dual process model of coping with bereavement: Rational and description. Death Studies, 23(3), 197-224. http://dx.doi.org/10.1080/074811899201046

Stroebe, M. \& Schut, H. (2010). The dual process model of coping with bereavement: A decade on. Death Studies, 61(4), 273-289. https://dx.doi.org/10.2190/OM.61.4.b

Stroebe, M., Schut, H., \& Stroebe, W. (2007). Health outcomes of bereavement. The Lancet, 370, 1960-1973. https://doi.org/10.1016/S0140-6736(07)61816-9

Thimm, J. C., \& Holland, J. M. (2017). Early maladaptive schemas, meaning making and complicated grief symptoms after bereavement. International Journal of Stress Management, 24(4), 347-367. https://doi.org/10.1037/str0000042

Thornton, G., Robertson, D. U., \& Mlecko, M. L. (2007). Disenfranchised grief and evaluations of social support by college students. Death Studies, 15(4), 355-362. https://dx.doi.org/10.1080/07481189108252440

Turner, J. C., Leno, E. V., \& Keller, A. (2013). Causes of mortality among American college students: A pilot study. Journal of College Student Psychotherapy, 27, 31-42. http://dx.doi.org/10.1080/87568225.2013.739022

Valentine, C., \& Woodthorpe, K. (2020). Supporting bereaved students at university: Balancing institutional standards and reputation alongside individual compassion and care. Death Studies, 44(1), 12-24. https://doi.org/10.1080/07481187.2018.1516702

Walker, A. C., Hathcoat, J. D., \& Noppe, I. C. (2011). College student bereavement experience in a Christian university. OMEGA - Journal of Death and Dying, 64(3), 241-259. http://dx.doi.org/10.2190/OM.64.3.d 
Understanding Bereavement among College Students: Implications for Practice and Research

Walker, P., \& Shaffer, M. (2007). Reducing depression among adolescents dealing with grief and loss: A program evaluation report. Health \& Social Work, 32(1), 67-68. http://dx.doi.org/10.1093/hsw/32.1.67

West, E. J. (2020). COVID-19 and Black grief in the academy. College Language Association, 63(2), 148-151. http://dx.doi.org/10.34042/claj.63.2.0148

Wolfelt, A. D. (2003). Understating your grief. Companion Press.

Wong, S. H. (2012). Does superstition help? A study of the role of superstitions and death beliefs on death anxiety amongst Chinese undergraduates in Hong Kong. OMEGA - Journal of Death and Dying, 65(1), 55-70. http://dx.doi.org/10.2190/OM.65.1.d

Yu, W., He, Li., Xu, W., Wang, J., \& Prigerson, H. G. (2016). Continuing bonds and bereavement adjustment among bereaved mainland Chinese. The Journal of Nervous and Mental Disease, 204(10), 758-763. http://dx.doi.org/10.1097/NMD.0000000000000550

Zamudio, G., Wang, C. D. C., \& Jin, L. (2020). Adult attachment, social self-efficacy, familismo, and psychological wellbeing: A cross cultural comparison. The Counseling Psychologist, 48(7), 922-952. http://dx.doi.org/10.1177/0011000020930637 